\title{
Relações afetivas entre mães e recém-nascidos a termo e pré-termo: variáveis sociais e perinatais
}

\author{
Ana Claire Pimenteira Thomaz \\ Maria Rejane Tenório de Lima \\ Carlos Henrique Falcão Tavares \\ Carlos Gonçalves de Oliveira \\ Universidade Federal de Alagoas
}

\begin{abstract}
Resumo
Sabe-se que a mãe assume um importante papel no desenvolvimento afetivo do bebê e conseqüentemente nas suas relações futuras. O trabalho objetivou analisar as primeiras relações afetivas entre mães de recémnascidos a termo e pré-termo na Maternidade do Hospital Universitário/UFAL, verificar as diferenças na relação afetiva entre esses dois grupos de mães e a importância do contato físico para a formação dessa primeira relação. Os instrumentos de pesquisa foram: entrevista e observação, tendo contado com a participação de 28 puérperas e seus recém-nascidos. O material obtido foi submetido à análise de conteúdo, tendo como referencial teórico a psicanálise. Os resultados mostraram que todas as mães estabeleceram ligações afetivas com seus bebês, mesmo nas situações em que o recém-nascido não foi planejado; a relação das mães pré-termo mostrou-se mais difícil, evidenciando que o contato físico é importante para a formação do vínculo afetivo mãe-bebê.
\end{abstract}

Palavras-chave: relações afetivas; pré-termo; recém-nascido a termo

\begin{abstract}
Affective bonds between mothers and full term and preterm infants: social and perinatal variables. It is known that a mother assumes an important role in the affective development of a baby and consequently in their future relationship The purpose of this paper was to analyze: (a) the first affective relationships between full-term and preterm infants mothers and their babies in the maternity ward of the University Hospital at the Federal University of Alagoas; (b) the differences in that relationship between these two groups of mothers; and (c) the importance of physical contact in the establishment of this bond. The instruments used in data collection were interviews and observation and the content analysis of 28 mothers and their newborns. Psychoanalysis was the theoretical approach adopted. The results showed that all mothers established an affective relationship with their babies, even when the pregnancy was not planned; however, in the preterm infants group this relationship was more difficult, showing that physical contact is important for the establishment of an affective bonding between mother and baby.
\end{abstract}

Keywords: affective relationship; preterm infant; full term infant

A história da assistência ao recém-nascido é marcada por momentos muitas vezes trágicos e desumanos. A bém de remédios específicos para o tratamento de infecções, levavam médicos e enfermeiras a adotar regras e normas muito rígidas (proibição de visitas, leitos em enfermarias individuais, etc.) como única forma de controle dessas infecções.

Com o advento da tecnologia e profissionais cada vez mais especializados, o foco de atuação não está voltado apenas para salvar vidas, mas, também, para a investigação dos fatores psicológicos que estão envolvidos na assistência aos pais e bebês a termo e pré-termo, melhorando a qualidade de vida e humanizando o atendimento.

Do ponto de vista do desenvolvimento global da criança, as relações afetivas entre mãe e bebê, possuem grande destaque nas pesquisas realizadas por vários autores que se dedicam ao estudo do binômio mãe-bebê. O afeto é essencial na infância. Sua importância é maior nessa idade que nos períodos posteriores. A atitude emocional da mãe e seu afeto orientam o bebê, conferindo qualidade de vida à sua experi- 
ência, já que o seu aparelho perceptivo e discriminação sensorial não estão maduros (Spitz, 1996).

A ligação afetiva é o vínculo que uma pessoa ou animal forma com outro indivíduo específico, sendo a formação das primeiras relações entre mãe e bebê os protótipos de todas as relações sociais futuras (Biaggio, 1996). A teoria da ligação afetiva é designada segundo Bowlby (1997) como:

Um modo de conceituar a propensão dos seres humanos a estabelecerem fortes vínculos afetivos com alguns outros, e de explicar as múltiplas formas de consternação emocional e perturbação da personalidade, incluindo ansiedade, raiva, depressão e desligamento emocional, a que a separação e perda involuntária dão origem. (p. 167)

Segundo o autor (Bowlby, 1977), o apego é conceituado como um vínculo do bebê para com sua mãe. Porém, o termo pode ser empregado de uma forma mais ampla, constituindo um vínculo nas duas direções, bebê-mãe e mãe-bebê (Klaus \& Kennell, 1993).

As pesquisas sobre o apego entre mãe-filho em unidades de tratamento intensivo tiveram início na década de 70 , quando os profissionais que trabalhavam nessas unidades, e que se esforçavam para salvar bebês prematuros, começaram a observar que algumas crianças voltavam para unidades de pronto-socorro vítimas de espancamento pelos próprios pais. O estudo desse fenômeno revelou que é freqüente crianças espancadas ou com dificuldades de desenvolvimento (sem causa orgânica) apresentarem história de prematuridade ou hospitalização precoce (Klaus \& Kennel, 1982).

O que poderia levar os pais a tomarem atitudes tão extremas na educação dos filhos, chegando a prejudicar o desenvolvimento dessas crianças? Será que eles não amam suficientemente seus filhos? Na verdade, o apego dos pais para com seu novo bebê não é instantâneo e automático com o nascimento. Ele não é instintivo, como é difundido popularmente; o vínculo deve ser visto como um processo contínuo para que exista a conscientização de suas complexidades e possíveis armadilhas, como por exemplo: o nascimento de um bebê prematuro e/ou com patologias que possam levar a quebra desse processo, acarretando dificuldades no relacionamento pais e filhos (Brazelton, 1988).

A natureza do relacionamento dos pais com o bebê é marcada pelo mundo mental das representações, pelo imaginário e subjetivo. Antes da existência do bebê real nos braços da mãe, existe o bebê imaginário. Esse é formado a partir das fantasias, dos sonhos, das brincadeiras de boneca e dos modelos de ser mãe (Stern, 1997).

Com a confirmação da gravidez, vários fatores podem perturbar inicialmente a mãe, gerando sentimentos de arrependimento e raiva, como dificuldades domésticas e financeiras e até problemas emocionais (Klaus \& Kennell, 1982). Não podemos considerar a gravidez como um evento isolado na vida de uma mulher. O contexto social, econômico, cultural e emocional influencia diretamente a forma como a mulher irá vivenciar esse momento na sua vida. A gravidez leva a uma readaptação dos mecanismos corporais como também a uma readaptação psicológica. O sonho de ser mãe e a disposição em assumir esse novo papel absorverão grande parte do tempo da gravidez (Brazelton, 1988). Os nove meses da gestação são um período útil e suficiente para que ocorra uma transformação importante na mulher, de forma que ela passe de um tipo de egoísmo para outro. A preocupação por si mesma estende-se para um outro ser, que em alguns meses estará sob sua responsabilidade (Winnicott, 1996).

Uma etapa importante na formação da relação maternofilial é a ocorrência dos movimentos fetais. Na fantasia da mãe o feto está começando a se comunicar através da variedade dos seus movimentos. O estilo de vínculo que ela formará com o filho sofre influência dessas representações mentais que a mulher tem de si mesma e do seu futuro bebê (Maldonado, 1997).

O parto é também um momento relevante para a formação do vínculo mãe-bebê. Os cuidados perinatais hospitalares influenciam essa relação. Uma das práticas questionadas diz respeito à utilização da anestesia no parto.

A ligação materno-infantil bem sucedida tem sido descrita como a capacidade da criança para despertar e ser reativa ao comportamento de tomar conta de sua mãe. Segue-se, então, que o produto mais bem sucedido de um parto é um recém-nascido desperto, alerta e reativo e uma mãe na mesma condição. (Sameroff, 1978, p. 977)

Depois do nascimento, os pais irão conhecendo o seu bebê à medida que cuidam dele e o bebê, por sua vez, também responde aos estímulos dos pais. Esse intercâmbio é adquirido de diferentes modos e de forma altamente individualizada. O período de tempo para a formação do apego íntimo e recompensador varia de pais para filhos. O melhor recurso para adquirir o papel de pai ou mãe é a liberdade de conhecer a si mesmo, seguindo as próprias inclinações, e o bebê sinaliza se o caminho está certo ou não (Brazelton, 1988). É um longo caminho que os pais percorrem para estabelecer uma ligação afetiva sólida com seus filhos. Sendo assim, a chegada de um bebê pré-termo constitui uma quebra nesse processo, repercutindo de forma significativa no relacionamento de pais e filho.

O primeiro ponto a ser ressaltado é que o parto prematuro, em geral, ocorre de forma urgente, privando a mãe da preparação psicológica do final da gravidez, causando um sentimento de ferida, de incapacidade, podendo levar a uma perturbação no seu fundamento narcisista de personalidade e identidade, ou seja, ela vive em um contexto de prematuridade psicológica (Ajuriaguerra \& Marcelli, 1991). Destarte, a mulher tende a se sentir prematura como mãe, pois foi pega de surpresa, não se sentindo pronta para receber o bebê no mundo. Além disso, o bebê pré-termo é menor e mais frágil, intensificando na mãe os temores comuns de não ser capaz de cuidar satisfatoriamente do filho. Quando o bebê corre risco de morte,os pais sentem medo de fazer ligação afetiva forte com o filho, porque ele pode não sobreviver (Maldonado, Dicktein, \& Nahoum, 1996). Esse momento é marcado pela coexistência de sentimentos ambíguos, especialmente quando o bebê é muito pequenino. A esperança de que ele viva é mesclada com desejos de morte 
que levam os pais a se sentirem culpados. O retorno para casa, quando ocorre, é vivido de forma dolorosa e traumatizante (Mazet \& Storeru, 1990).

Questão importante diz respeito ao fato de que esses pais irão enfrentar a rotina de uma UTI neonatal onde o seu bebê precisa permanecer para sobreviver: "De repente, o primeiro colo desse bebê é a incubadora”. Esse bebê que esperavam estar acariciando, mostrando aos familiares e amigos “Sua Majestade o Neném - está cheio de fios, picado por agulhas, sob luzes, aparelhos sofisticados e correndo risco de morrer” (Souza \& Barros, 1999, p. 132). O sentimento dos pais a respeito das “máquinas salvadoras” pode ser ambivalente; por uma parte, expectativa quase mágica em relação a elas, graças às quais sua criança sobrevive e os obriga a uma missão completa; por outra parte, coexiste um sentimento de repúdio devido à distância que essas máquinas interpõem entre eles e a criança e, conseqüentemente, sentem-se excluídos (Viziello, Zorzi, \& Bottos, 1992). Não é de admirar que uma mãe nessa situação queira fugir ou protegerse sob a depressão para não cuidar do bebê. Essas respostas não podem ser consideradas anormais e sim respostas previsíveis. O surpreendente é que os pais conseguem superar esses sentimentos, começam tudo novamente, criando um vínculo com o bebê. Para tanto, eles passam por "estágios” à medida que formam o apego ao bebê prematuro. Antes, porém, vem uma reação de luto, que é inevitável. Esta reação é pela perda do bebê perfeito que esperavam, como também pelos “defeitos" que produziram no bebê. Esse sentimento de culpa pode ser consciente ou inconsciente, tendo justificativa ou não. Para superar esse sentimento é preciso tempo e um árduo trabalho pessoal (Brazelton, 1988).

Por último, é preciso incluir o hospital nesse contexto. A equipe de saúde, em algumas ocasiões, pode distanciar ainda mais a relação mãe-filho. Quando o grupo se identifica com o bebê, dando-lhe toda assistência, mas negligenciando as necessidades de dependência e cuidados da mãe, estabelece-se uma relação de oposição. E, sendo assim, a equipe torna-se incapaz de atender mãe e filho (Cresti \& Lapi, 1997).

O quadro teórico acima levantado buscou traçar de forma didática e cronológica o percurso do desenvolvimento afetivo mãe-bebê, que tem seu início antes mesmo da gravidez e se estende até o convívio dessa díade após o nascimento da criança. Por esse motivo optamos por trabalhar com autores psicanalíticos de correntes diferentes que abordassem em suas teorias as categorias a serem pesquisadas. Ressaltamos a inexistência de trabalhos com essa temática em nossas maternidades, tornando necessário incluir o estudo das relações afetivas como uma categoria fundamental. Não só para a compreensão de um fenômeno psicológico, mas, principalmente, para contribuir com a atuação dos profissionais das maternidades e unidades de terapia intensiva neonatal, que prestam assistência diária às mães e aos recémnascidos a termo e pré-termo.

Assim, os objetivos do presente estudo foram: analisar as primeiras relações afetivas entre mãe e recém-nascido a termo e pré-termo; verificar as diferenças nessa relação e a importância do contato físico entre mães e bebês para a formação das primeiras relações afetivas e levantar dados sobre a história da gravidez e a condição sócio-econômica da mesma.

\section{Método}

Esse trabalho foi desenvolvido na UTI neonatal e na maternidade Dr. Mariano Teixeira do Hospital Universitário da Universidade Federal de Alagoas/UFAL. A maternidade localiza-se no $2^{0}$ andar desse hospital e funciona no sistema de alojamento conjunto, garantindo às mães contato direto com seus filhos, proporcionando-lhes a oportunidade para os primeiros cuidados do bebê sob a orientação dos profissionais responsáveis. Cada enfermaria do alojamento conjunto possui 4 leitos e banheiro para as mães.

A UTI neonatal está localizada no $3^{\underline{0}}$ andar do HU/UFAL, na clínica pediátrica. A puérpera de parto pré-termo permanece internada no alojamento conjunto ( $2^{\underline{0}}$ andar), tendo livre acesso para visitar o filho na UTI neonatal, sem restrição de horários, mesmo após a alta hospitalar. As mães só não têm acesso à UTI neonatal quando a equipe médica precisa realizar procedimentos invasivos ou de urgência.

A maternidade do hospital universitário recebe pacientes tanto da capital como do interior do Estado de Alagoas. Não há unidades de terapia intensiva neonatal nos outros municípios, sendo as gestantes de alto risco encaminhadas para Maceió. A demanda assistida é de baixo poder aquisitivo, algumas pacientes possuem planos de saúde, contudo estes não cobrem a permanência dos bebês em UTI neonatal.

\section{Participantes}

Participaram do estudo 28 mulheres (e seus bebês), escolhidas de forma aleatória simples. Destas, 18 eram mães de recém-nascidos a termo $(\mathrm{RNT})$ e 10 de recém-nascidos prétermo (RNPT).

No presente trabalho, definimos bebê pré-termo tomando como base a World Health Organization (WHO, 1950), que considerou recém-nascido pré-termo toda criança nascida viva com idade gestacional (IG) inferior a 37 semanas completas e utilizamos o significado do apego segundo definição de Klaus \& Kennell (1993).

Os dados numéricos apresentados na Tabela 1 não foram submetidos a análise estatística; visam apenas possibilitar uma compreensão da condição socioeconômica das 20 mães que participaram da entrevista.

A referida tabela mostra que a idade das 20 puérperas entrevistadas variou entre 15 e 37 anos. As mães de RNPT eram mais jovens e $60 \%$ delas tinham menos de 20 anos. Já entre as mães de RNT, apenas 20\% estavam nessa faixa etária.

Com relação à escolaridade, observamos que 20 e 30\% das mães de RNT e RNPT, respectivamente, concluíram o ensino médio. 60\% das de RNPT não conseguiram concluir o ensino fundamental e $10 \%$ das mães de ambos os grupos eram analfabetas. Das mães de RNT e RNPT entrevistadas, 40 e 30\%, respectivamente eram do interior. Quanto à residên- 
Tabela 1

Distribuição dos dados sócio-demográficos das mães dos recémnascidos a termo e pré-termo entrevistadas na maternidade Dr. Mariano Teixeira - HU/UFAL, 2003.

\begin{tabular}{lllllll}
\hline \multicolumn{1}{c}{ Categorias } & RNT & $\%$ & RNPT & $\%$ & Total $(n)$ & $\%$ \\
\hline Idade & & & & & & \\
$\quad$ 15-19 & 2 & 20 & 6 & 60 & 08 & 40 \\
$20-25$ & 6 & 60 & 3 & 30 & 09 & 45 \\
26-37 & 2 & 20 & 1 & 10 & 03 & 15 \\
Escolaridade & & & & & & \\
$\quad$ Analfabeto & 1 & 10 & 1 & 10 & 02 & 10 \\
N.C.E.F & 5 & 50 & 6 & 60 & 11 & 55 \\
C.E.F & 2 & 20 & - & 00 & 02 & 10 \\
C.E.M & 2 & 20 & 3 & 30 & 05 & 25 \\
Procedência & & & & & & \\
Interior & 4 & 40 & 3 & 30 & 07 & 35 \\
Capital & 6 & 60 & 7 & 70 & 13 & 65 \\
Residência & & & & & & \\
$\quad$ Própria & 7 & 70 & 6 & 60 & 13 & 65 \\
Alugada & 3 & 30 & 4 & 40 & 07 & 35 \\
Renda (SM) & & & & & & \\
$\quad$ <1 & - & - & 1 & 10 & 01 & 05 \\
$\quad$ 1-3 & 7 & 70 & 2 & 20 & 09 & 45 \\
$\quad$ 3-8 & 1 & 10 & 2 & 20 & 03 & 15 \\
$\quad$ N & 2 & 20 & 5 & 50 & 07 & 35 \\
Trabalhava & & & & & & \\
$\quad$ Sim & 1 & 10 & 3 & 30 & 04 & 20 \\
$\quad$ Não & 9 & 90 & 7 & 70 & 16 & 80 \\
Paridade & & & & & & \\
$\quad$ Primigesta & 5 & 50 & 6 & 60 & 11 & 55 \\
$\quad$ Segundigesta & 2 & 20 & 2 & 20 & 04 & 20 \\
$\quad$ Multigesta & 3 & 30 & 2 & 20 & 05 & 25 \\
\hline
\end{tabular}

Nota. RNT = recém-nascidos a termo; RNPT = recém-nascidos a pré-termo; N.C.E.F = não concluiu o ensino fundamental; C.E.F = concluiu o ensino fundamental; C.E.M = concluiu o ensino médio; $\mathrm{S} . \mathrm{M}$ = salário mínimo; $\mathrm{N}$ = não sabe informar.

cia, 65\% das mães moravam em casa própria e o número de pessoas por residência variou entre duas a oito pessoas. Salientamos ainda que $40 \%$ das mães de RNT e $70 \%$ de RNPT residiam com os pais, irmãos ou sogros.

A renda familiar de $70 \%$ das mães de RNT e 20\% de RNPT estava entre um a três salários mínimos. Pudemos também observar que $20 \%$ das mães de RNT e 50\% de RNPT não sabiam informar a renda familiar. Isso se justifica pelos seguintes fatos: seus companheiros não tinham trabalho fixo, dependiam financeiramente de pais, irmãos e/ou sogros ou estavam inseridos no mercado de trabalho informal. Apenas $10 \%$ das mães de RNT e 30\% de RNPT trabalhavam.

Outro dado importante considerado foi o número de filhos. A grande maioria das mães, em nosso estudo, era primigesta, sendo 50\% de RNT e 60\% de RNPT. De acordo com o número de consultas durante a gravidez, 70\% das mães de RNT e 30\% de RNPT fizeram o pré-natal (dados não apresentados na tabela).

Com relação à amamentação, 100\% das mães de RNT estavam amamentando. Entre os RNPT, 70\% dos bebês não estavam se alimentando de leite materno, 20\% tomavam leite materno pela sonda e apenas $10 \%$ estavam sendo amamentados e usando complemento (fórmula infantil) no copinho.

\section{Procedimentos}

Os dados da pesquisa foram coletados no período de março a junho de 2000, nos turnos da manhã e da tarde, sem dias específicos na semana. Os instrumentos de pesquisa para coleta de dados foram: entrevista e observação.

A entrevista foi semi-estruturada, com perguntas referentes à identificação (dados sócios demográficos), história da gravidez (se a criança foi desejada, reação do companheiro frente à gravidez, se fez acompanhamento pré-natal, etc.), parto e pós-parto (sentimento em relação ao nascimento do bebê, dados de amamentação, planos para o futuro do bebê, etc.).

Para a realização da entrevista foi feito inicialmente levantamento das mães de RNT e RNPT, utilizando, para isso, o mapa da enfermagem com a relação das pacientes. O número do leito foi sorteado, confirmando-se, a partir daí, o nome da mãe. Participaram dela, 10 mães de RNT e 10 de RNPT. Todas as entrevistas foram gravadas e transcritas na íntegra para a análise.

O tipo de observação utilizada foi a não-estruturada na qual, segundo Alves-Mazzotti e Gewandsznajder (1999), “os comportamentos a serem observados não são predetermina- 
dos, eles são observados e relatados da forma como ocorrem, visando descrever e compreender o que está ocorrendo numa situação" (p. 166). As mães de RNT foram observadas na sala de higienização (onde os bebês tomam banho) e no alojamento conjunto; as mães de RNPT na UTI Neonatal. Participaram da observação seis mães de RNPT, que também fizeram parte das entrevistas, e 8 mães de RNT, estas não tendo sido entrevistadas. Não foi possível realizar a observação com as mesmas mães de RNT que fizeram a entrevista, pois o tempo máximo de permanência no hospital para puérperas de baixo risco era de 48 horas. Já as mães de RNPT chegam a freqüentar o hospital por até 3 meses, o que facilitou a realização das observações.

O objetivo da observação foi verificar o comportamento das mães nos cuidados com o bebê (amamentar, dar banho, etc.) e, também, a dinâmica de funcionamento da UTI neonatal. As anotações foram feitas tanto na hora da observação, como posteriormente. Todo procedimento foi realizado após consentimento livre e esclarecido das mães e autorizado pelo Comitê de Ética em Pesquisa da Universidade Federal de Alagoas/UFAL.

\section{Análise dos dados}

O presente trabalho é um estudo de metodologia qualitativa. O estudo dos dados foi feito através da análise de conteúdo, que se constitui em "um conjunto de técnicas de análise das comunicações” (Bardin, 1977), baseando-se nas seguintes categorias temáticas: sentimento das mães ao descobrirem que estavam grávidas; do companheiro ao ficar ciente da gravidez da mulher; das mães, no momento em que o feto mexeu pela primeira vez; o imaginário das mães sobre como o bebê iria ser ao nascer; percepção das mães sobre a possibilidade dos bebês nascerem prematuramente; sentimentos das mães com o nascimento do filho e o seu pensamento sobre o futuro dos bebês. O referencial teórico adotado nesta pesquisa não se centrou apenas no pensamento de um teórico, mas abordamos vários autores psicanalíticos que se referiram às categorias pesquisadas. O comportamento das mães observadas também foi interpretado com base no mesmo referencial.

\section{Resultados e discussão}

Observação do comportamento das mães na UTI neonatal e alojamento conjunto

A UTI neonatal é dividida em três espaços. No lado esquerdo ficam os bebês que precisam de cuidados intensivos; no centro, sala com armários para o material hospitalar além de pia, balcões para preparo de medicação, etc.; e, à direita, encontram-se os bebês que inspiram apenas cuidados intermediários. O movimento dos residentes, médicos, enfermeiras, auxiliares de enfermagem e fisioterapeutas é intenso, para a realização de exames e outros procedimentos médicos. Em meio a toda a movimentação, as mães, muitas vezes, entram e saem da UTI sem chegar a conversar com os médicos, estabelecendo maior contato apenas com as auxiliares de enfermagem.

Na observação do comportamento das mães na UTI neonatal obtivemos informações importantes sobre a relação afetiva dos dois grupos (mães de RNT e RNPT). As mães de RNT observadas no alojamento conjunto colocavam os seus bebês na cama, apesar de existir berço ao lado. Esse comportamento facilitava os cuidados com o bebê, além de deixá-lo mais próximo das mães que podiam acariciar, conversar e perceber as necessidades da criança. Como exemplo, uma mãe, ao ver o filho chorar, enrolou-o enquanto conversava com ele, acreditando que o bebê estava sentindo frio e o bebê, realmente, parou de chorar. Das 10 mães do estudo apenas uma, durante o período de observação, diante do filho que persistentemente chorava no berço, não foi ao seu encontro, continuando a se pentear no banheiro.

Tulha (1979) ressalta que para ser capaz de conhecer as sutilezas das necessidades do bebê é preciso cuidar da criança como um indivíduo que possuí características, gestos e preferências próprias. Isso só ocorre quando há uma relação afetiva entre a pessoa que cuida e a criança, processo que começa na gravidez com a regressão, quando a mulher se prepara para receber o bebê. No caso dessa mãe em particular que não foi ao encontro do filho que chorava no berço, ela, talvez, não tenha podido vivenciar o processo de regressão na gravidez, levando, então, a tentativa de adaptar as necessidades do bebê às suas. É comum também que as mães tenham medo de que os bebês fiquem mimados caso os coloquem no colo todas às vezes que chorem.

Em relação ao banho do bebê, todas as mães (10) de RNT sentiam receio, solicitando sempre ajuda das auxiliares de enfermagem, responsáveis pela assistência às mães do alojamento conjunto. O medo em derrubar o bebê ou machucá-lo, por sua fragilidade, está presente nos comentários realizados pelas mães nesse momento. Maldonado (1994) afirma que os receios e medos nos cuidados do bebê fazem parte do aprendizado do papel de mãe, especialmente quando o filho é o primogênito.

A seqüência do comportamento das mães de RNPT observadas que iam visitar os bebês nas incubadoras era a mesma descrita por Klaus \& Klaus (1989). Primeiro tocavam nas extremidades dos bebês (braços e pernas) e depois no tronco. Também acariciavam seus rostos no mesmo plano de rotação paralelo aos dos bebês (posição em face). Esses comportamentos são comuns nas mães dos recém-nascidos de uma maneira geral.

Gomes, Quayle, Neder, Leone e Zugaib (1997) apontam que enquanto a mãe não pode segurar o filho, o contato físico através do toque é desejável, assim como os cuidados para manter a produção do leite materno. O seu armazenamento deve ser estimulado e, quando possível, ser dado por sonda, até o momento em que, então, a mãe possa segurá-lo e amamentá-lo. Isto contribui para a manutenção do vínculo, pois a mãe se sente satisfeita em dar algo que é seu, aproximase da "normalidade", fazendo com que não se sinta excluída, minimizando a insegurança, tornando-a, com o tempo, mais participativa no cuidado com o filho, desempenhando o seu papel de forma espontânea e natural.

Quando os bebês estavam em berços na UTI neonatal, as mães possuíam mais liberdade para interagir normalmente com seus filhos; colocá-los nos braços, amamentar ou ali- 
mentar o bebê com leite materno pela sonda, beijar, etc. A amamentação, além de ser um processo fisiológico, promove uma comunicação psicossocial ampla entre mãe e bebê, aprofundando o contato e suavizando o trauma da separação provocado pelo nascimento (Maldonado, 1997). Em termos vitais, é mais importante o ato de segurar e manipular o bebê do que a experiência concreta da amamentação (Winnicott, 1996). As mães também participavam mais ativamente dos cuidados básicos do bebê com a orientação das auxiliares de enfermagem. As mães de RNT têm maior oportunidade de estabelecer esse contato de imediato com seus filhos no alojamento conjunto, diferindo das mães de recém-nascidos prétermo, que não podem vivenciar de imediato a experiência de segurar e manipular os seus filhos.

Além das dificuldades de ficarem separados dos filhos, os pais na UTI neonatal enfrentam a angústia, tensão e apreensão em relação à situação do bebê. De acordo com a observação do comportamento realizado com as mães verificou-se que o acesso livre dos pais foi muito importante para o relacionamento pais-bebê. $\mathrm{O}$ ver, tocar e ajudar a cuidar do filho alivia em parte a angústia e a insegurança. O que foi constatado através da menor solicitação de ajuda às auxiliares de enfermagem, o manuseio mais seguro dos bebês e a própria expressão no olhar dos pais. A criança também é beneficiada nesse contato, pois o bebê pré-termo possui as mesmas necessidades emocionais dos nascidos a termo (Maldonado, 1994).

A observação das mães na UTI neonatal mostrou que o movimento de rotina dos profissionais pode ou não influenciar no seu comportamento, quando estão com seus bebês. Uma das mães sempre se dispersava olhando para os outros bebês e para qualquer procedimento realizado pelos profissionais de saúde, enquanto outra, mesmo quando se realizavam procedimentos pouco comuns, continuava olhando para o filho, que era segurado de frente para ela. Observou-se também que as mães pouco conversavam com os bebês, especialmente quando estavam nas incubadoras.

A UTI neonatal do Hospital Universitário possui equipamentos e profissionais capacitados para o atendimento às crianças prematuras. Porém, para os pais toda essa estrutura mobiliza sentimentos de medo e perda, especialmente quando vão ver o bebê pela primeira vez.

\section{Dados das entrevistas das mães de RNT e RNPT}

Os sentimentos de uma mulher em relação ao filho que está sendo gestado são complexos. O contato com ambivalência é comum para a mulher - querer ou não querer, aceitar ou não aceitar, alegria ou temor. Ter um filho significa um compromisso para o resto da vida. Isso suscita não apenas um sentimento, mas uma gama de sensações e de emoções de intensidades diferentes (Maldonado et al., 1996).

No presente trabalho observou-se a mistura de sentimentos quando as mães de RNT e RNPT tiveram a confirmação da gravidez:

Feliz. Porque eu já tinha vontade de ter antes; aí, minha ansiedade era tão grande que ela não vinha. Quando eu tirei da cabeça um pouco, aí ela nasc... eu soube que eu tava grávida. (RNT7, 19 anos, $1^{0}$ filho)
Naquela hora, mesmo que eu não tivesse...eu, desconfiado e dizia: meu Deus eu não posso ficar grávida agora. Mas quando eu soube que realmente estava, eu fiquei...fiquei pasma, eu quis aquilo, fiquei muito feliz, dentro de mim veio uma felicidade imensa. (RNPT1, 22 anos, $1^{\circ}$ filho)

Tanto as mães de RNT como as de RNPT vivenciaram sentimentos comuns diante da responsabilidade de ter um filho. As falas sinalizam a ambigüidade do desejo de ter ou não um filho, processo que precisa ser superado para que se possa estabelecer um vínculo com o futuro bebê. Os sentimentos e reações apresentados por essas mães estavam associados com o momento de vida presente. Algumas disseram que não queriam filhos no momento porque estavam trabalhando, pouco tempo de casamento, sofrimento na primeira gestação, medo da família não aceitar (solteiras) e abandono do companheiro, tendo que assumir todas as responsabilidades sozinhas.

As mudanças na vida dos pais são mais radicais na primeira gestação, pois antes existe apenas o vínculo entre homem e mulher e, com a gravidez, existe um pai e uma mãe criando um vínculo com o filho. A relação que antes era a dois, passa a ser a três. A complicada transição dos papéis de homem, mulher e filho, para a condição de pais acarreta expectativas, anseios e temores (Maldonado et al., 1996).

Uma figura importante para a mulher durante a gestação é o seu companheiro, que também pode vivenciar sentimentos ambíguos, quando fica ciente da gravidez da mulher. Diante da situação da gravidez, os fatores emocionais vividos pelo homem (alegria, ansiedade, negação à sua participação e reconhecimento, etc.) são resultados de mecanismos psíquicos, que estão relacionados com experiências anteriores ao seu desenvolvimento, como também da sua (trans)formação da identidade de homem, podendo ampliar ou bloquear as emoções expressas ou negadas (Souza, 1997).

Os pais de RNT tiveram aparentemente uma melhor reação quando souberam da gravidez que os pais de RNPT. Salientamos também que quando a gravidez acontece dentro de um relacionamento bem estabelecido, a aceitação do homem fica mais fácil.

Ah! Ele ficou alegre, não tinha esse negócio que eu dizia: "vou tomar remédio pra matar se eu souber que tô grávida”. Ele disse: "Vá! Tome! Isso pega processo, num sei o que, aí eu não tomei não. (RNT5 31 anos, $2^{\underline{0}}$ filho)

O pai da criança só disse que não ia assumir porque não era dele, né? Eu disse: tudo bem; não tem problema não. (RNPT4, 17 anos, $1^{\underline{0}}$ filho)

Um fato importante para a relação afetiva mãe-bebê é o momento em que o feto mexe pela primeira vez. Os movimentos do feto desde a décima segunda semana são precoces, bruscos em flexões e extensões, contudo a mãe só sente os movimentos do filho mais tarde e a aceitação dessa percepção é o reconhecimento da realidade do filho (Soulé, 1987).

Observam-se a seguir as falas das mães sobre como se sentiram quando a criança mexeu pela primeira vez: 
O que que eu senti? Eu me senti agoniada porque cada vez que ele mexia era que as dores doía mais, aquelas dores descendo pra baixo muito forte. (RNT5, 31 anos, $1^{0}$ filho)

Quando a gente vê, a gente percebe que tem uma coisinha nascendo lá! Porque antes de mexer é só você, tá no resultado do exame que tá grávida, e pronto. Mas quando mexe! Que você sabe que tem uma vida aí dentro, aí é emocionante! Eu mesmo me senti muito bem quando ela mexeu! (RNPT5, 27 anos, $1^{\circ}$ filho)

Nessas falas podemos encontrar duas situações diferentes: na primeira os movimentos fetais representam sofrimento para a mãe, na segunda a confirmação concreta da existência de uma vida dentro de si. Klaus e Kennel (1993) observam que diante das primeiras manifestações de vida do bebê a mãe, geralmente, começa a fantasiar como o bebê será, começando a atribuir características da personalidade humana, desenvolvendo sentimentos de apego. A gravidez pode ser bem mais aceita, ocorrendo mudanças significativas na sua atitude com o feto. Essa mudança interna é evidenciada externamente na preparação materna como a escolha de um nome e a compra de roupas para o bebê.

Durante a gravidez a futura mãe começa a imaginar como o bebê irá ser quando nascer, como mostram as seguintes colocações:

Meu sonho era ter um menino de olhos azuis, igual o meu pai e ele nasceu com os olhinhos azul, branquinho com os olhinhos azul. (RNT10, 24 anos, $2^{0}$ filho)

Eu imaginava que ela ia ser igual o menino, ia ser galeguinha dos olhos azul, ia nascer normal, às vezes imaginava de ser homem, de ser mulher, sonhava tanta da coisa, quando eu sonhava eu ficava pensando, botando aquilo na cabeça. Não (não corresponde com bebê que imaginava) Um pouco, às vezes eu imaginava de ela nascer moreninha, porque meu pai é bem moreno, mas eu acho que não vai nascer branca mesmo, aí nasceu parda, quando crescer ela vai ficar moreninha. (RNPT9 19 anos, $5^{-0}$ filho)

A primeira mãe falou que seu bebê nasceu como ela tinha imaginado durante a gravidez. Para a segunda mãe, o bebê não nasceu como ela imaginava. Contudo, quando ela depois diz que o bebê nasceu "um pouquinho" como imaginava, já começa a elaborar o luto pela perda da criança imaginária e entrar em contato com a criança real, estabelecendo uma ligação afetiva mais concreta. É preciso “matar” a criança idealizada para que ocorra a aceitação da criança real, como afirma Noronha (1997). Nota-se que a maioria das mães esperava que seus filhos fossem parecidos com o esposo ou com o próprio pai.

Durante a gravidez algumas mães chegaram a pensar que os seus bebês pudessem nascer prematuramente. Os motivos das mães pensarem dessa forma estavam relacionados a: complicações clínicas, experiência de amigas e parentes que tiveram filhos pré-termo, a sua própria experiên- cia e devido ao feto não mexer muito. Vale ressaltar que algumas mães não sabiam explicar porque pensaram nessa possibilidade.

As mães entrevistadas também falaram sobre como estavam se sentido com o nascimento dos filhos:

Feliz da vida, né? Veio com saúde, graças a Deus, perfeita, só tenho que agradecer a Deus. (RNT7 19 anos, $1^{0}$ filho).

Fiquei alegre e, ao mesmo tempo, triste, porque achava eu que ele não ia resistir, até agora graças a Deus ele está bem, só não tá melhor porque ele tá lá em cima, não tá comigo. (RNPT2, 19 anos, $2^{\underline{0}}$ filho)

Brazelton (1988) comenta que os pais de RNT depois do nascimento de seu filho se sentem completamente "fora do ar”, com uma espécie de disponibilidade resultante da excitação, do medo, do alívio e da ansiedade. Sentem-se aliviados por terem feito tudo, gratidão pelo fato do bebê nascer e êxtase por ele ser normal e, por fim, um sentimento grandioso ao tomar conta de uma criatura pequena e dependente. Já para a mãe de RNPT, em decorrência da emergência do fato, fica mais difícil a manutenção do vínculo com o bebê, devido às dúvidas acerca de sua sobrevivência, assim como os sentimentos inexpressíveis de culpa por tê-lo colocado em uma situação de perigo. O que o autor comenta esteve presente nas declarações apresentadas, a felicidade da mãe de RNT por ter colocado no mundo um bebê perfeito e os sentimentos ambíguos da mãe de RNPT em virtude do seu bebê estar passando por uma situação delicada.

Os dados mostram que houve uma reversão dos sentimentos das mães que ficaram tristes ou não aceitaram a gravidez, pois todas as mães, mesmo as de RNPT e que apresentaram sentimentos ambíguos, relataram sentimentos positivos (alegria, felicidade) com o nascimento do filho.

Quando abordadas sobre o futuro dos bebês, a maioria das mães relatou que não havia pensado ainda:

Não, ainda não. Isso eu tenho que sentar com o papai dele e a gente pensar aí. (RNT1, 25 anos, $1^{\circ}$ filho)

Não, agora no momento não, até agora não. Ele aqui? Sabe nem sei se vai se criar, meu Deus! (RNPT2 19 anos, $2^{\underline{0}}$ filho)

As mães não tinham pensado no futuro do filho, mas o que difere de uma mãe de RNT para uma mãe de RNPT é a incerteza relativa ao bebê resistir, ou não. Ela vive um luto antecipado pela possível perda do filho que, de acordo com Cramer (citado por Klaus \& Kennel, 1993), quando é muito intenso leva as mães a não considerarem futuros relacionamentos com o filho. Evitam falar sobre o bebê durante visitas de parentes e amigos.

Todos os dados apresentados são indicativos de que a relação afetiva mãe-filho não tem seu início com o nascimento do bebê. Ela já é marcada pelos vários fatores que ocorrem durante a gestação. Para que essa relação se solidifique após o nascimento, muitas mães precisam elaborar as perdas e mudanças que uma gravidez traz para suas vidas. 


\section{Conclusões}

Quanto à condição socioeconômica das mães e aos dados sobre a história da gravidez, concluiu-se que: as mães de RNT e RNPT apresentavam baixas condições socioeconômicas; as mães de RNPT eram mais jovens e na maioria (60\%) prímiparas; o pré-natal foi realizado em maior percentagem (70\%) pelas mães de RNT; todas as mães de RNT amamentaram seus filhos, enquanto apenas uma mãe de RNPT amamentou o seu.

Quando se analisaram as primeiras relações afetivas entre mãe e recém-nascido a termo e pré-termo, as diferenças nessa relação e a importância do contato físico entre mães e bebês para a formação das primeiras relações afetivas, foi verificado que: (a) não houve diferença entre as mães dos RNT e RNPT em relação aos sentimentos quando da confirmação e aceitação da gravidez, da responsabilidade de ter um filho e da percepção dos primeiros movimentos fetais; (b) as mães de RNPT vivenciaram o nascimento de seus filhos de forma diferente das de RNT; (c) observou-se que a ligação afetiva das mães de bebês pré-termo estava permeada pelo "fantasma" da morte, mesmo que de forma não explícita nos discursos; (d) em relação aos cuidados com os bebês, todas as mães apresentaram dificuldade e medo, sendo a insegurança maior nas de RNPT; e (e) o contato físico com os bebês foi importante para a ligação afetiva mãe-bebê, e todas as mães sentiram a necessidade de estarem próximas aos filhos, sendo que a relação de segurança no cuidado com o seu bebê foi mais demorada nas mães de RNPT.

Face ao exposto, ficou evidenciado que as mães de RNPT precisam de mais apoio da equipe hospitalar que as mães de RNT. É importante a existência de um espaço para ouvir essas mães, compreendendo o momento em que estão vivendo e incentivando a sua participação na rotina da UTI neonatal.

Assim, a equipe não estará apenas salvando a vida do bebê, mas contribuindo também para a formação de uma relação afetiva mais sólida entre mãe e bebê pré-termo. Porém, para que isso possa vir a acontecer é preciso que haja um repensar, não só das práticas de assistência nos hospitais, mas das próprias condutas dos profissionais das unidades de terapia intensiva neonatal.

\section{Referências}

Ajuriaguerra, J., \& Marcelli, D. (1991). Manual de psicopatologia infantil. Porto Alegre: Artes Médicas.
Alves-Mazzotti, A. J., \& Gewandsznajder, F. (1999) O método nas ciências naturais e sociais: pesquisa quantitativa e qualitativa. São Paulo: Pioneira.

Bardin, L. (1977). Análise de conteúdo. Lisboa: Edições 70.

Biaggio, A. M. B. (1996). Psicologia do desenvolvimento. Petrópolis: Vozes.

Bowlby, J. (1997). Formação e rompimento dos laços afetivos. São Paulo: Martins Fontes.

Brazelton, T. B. (1988). O desenvolvimento do apego: uma família em formação. Porto Alegre: Artes Médicas.

Cresti, L., \& Lapi, I. (1997). O esboço da relação mãe/bebê e a instituição hospitalar: díade ou tríade? In M-B. Lacrax, \& M. Monmayrant (Orgs.), A observação de bebês: os laços do encantamento. Porto Alegre: Artes Médicas.

Gomes, A. L., Quayle, J., Neder, M., Leone, C. R., \& Zugaib, M. (1997). Mãe- bebê pré-termo: as especificidades de um vínculo e suas implicações para a intervenção multiprofissional. Revista Ginecologia \& Obstetrícia, 8, 205-208.

Klaus, M., \& Kennell, J. (1982). Assistência aos pais. In M. H. Klaus \& A. A.Fanroff (Orgs.), Alto risco em neonatologia. Rio de Janeiro: Interamericana.

Klaus, M., \& Kennell, J. (1993) Pais e bebês: a formação do apego. Porto Alegre: Artes Médicas.

Klaus, M., \& Klaus, P. (1989). O surpreendente recém-nascido. Porto Alegre: Artes Médicas.

Maldonado, M. T. (1994). Como cuidar de bebês e crianças pequenas. São Paulo: Saraiva.

Maldonado, M. T. (1997). Psicologia da gravidez. São Paulo: Saraiva.

Maldonado, M. T., Dicktein, J., \& Nahoum, J. C. (1996). Nós estamos grávidos. São Paulo: Saraiva.

Mazet, P., \& Stoleru, S. (1990). Manual de psicopatologia do recém-nascido. Porto Alegre: Artes Médicas.

Noronha, D. T. (1997). Gravidez: situação de crise. Rio de Janeiro: Revinter.

Sameroff, A. (1978). Necessidades psicológicas da mãe nas interações maternoinfantis precoces. In G. B. Avery (Org.), Neonatologia, fisiologia e cuidados do recém-nascido. São Paulo: Artes Médicas.

Soulé, M. (1987). O filho da cabeça, o filho imaginário. In T. B. Brazelton (Org.), A dinâmica do bebê. Porto Alegre: Artes Médicas.

Souza, E. M. C. D., \& Barros, M. L.G. A. (1999). O mal-estar da culta. In M. D. Moura (Org.), Psicanálise e hospital: a criança e sua dor. Rio de Janeiro: Revinter.

Souza, S. L. (1997). O papel do pai. In M. Zugaib, J. Tedesco, \& J. Quayle (Orgs.), Obstetrícia psicossomática. São Paulo: Atheneu.

Spitz, R. A. (1996). O primeiro ano de vida. São Paulo: Martins Fontes.

Stern, D. N. (1997). A constelação da maternidade. Porto Alegre: Artes Médicas.

Tulha, O. M. P. A. (1979). O vínculo mãe-filho e as necessidades emocionais da criança. In D. U. M. Machado (Org.), Ação psicoprofilática do pediatra. São Paulo: Sarrier.

Vizziello, G. F., Zorzi, C., \& Bottos, M. (1992). Los hijos de las máquinas: la vida de los niños internados en terapias intensivas neonatales. Buenos Aires: Nueva Visión.

World Health Organization (1950). Technical report series $n^{0} 25$.

Winnicott, D. W. (1996). Os bebês e suas mães. São Paulo: Martins Fontes.

Ana Claire Pimenteira Thomaz, doutora em Pediatria pela Faculdade de Medicina de Ribeirão Preto, Universidade de São Paulo, é professora adjunta na Universidade Federal de Alagoas. Endereço para correspondência: Rua 06A/186, Conjunto Arvoredo, Barro Duro; Maceió, AL; CEP 57046-040. Tel. (82) 3328-1966. Email: ana.claire@uol.com.brou ana.claire@fapeal.br

Maria Rejane Tenório de Lima, psicóloga pela Universidade Federal de Alagoas.

Carlos Henrique Falcão Tavares, doutor em Pediatria pela Faculdade de Medicina de Ribeirão Preto, Universidade de São Paulo, é professor adjunto na Universidade Federal de Alagoas.

Carlos Gonçalves de Oliveira, doutor em Pediatria pela Faculdade de Medicina de Ribeirão Preto, Universidade de São Paulo, é professor adjunto na Universidade Federal de Alagoas. 